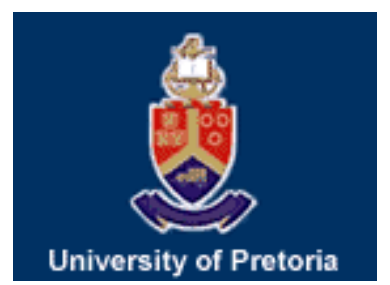

University of Pretoria

Department of Economics Working Paper Series

Economic Growth and Inequality: Evidence from the Young Democracies of South America

Manoel Bittencourt

University of Pretoria

Working Paper: 2013-01

January 2013

Department of Economics

University of Pretoria

0002, Pretoria

South Africa

Tel: +27 124202413 


\title{
Economic Growth and Inequality: Evidence from the Young Democracies of South America
}

\author{
Manoel Bittencourt* \\ University of Pretoria
}

January 17, 2013

\begin{abstract}
We investigate in this paper whether income growth has played any role on inequality in all nine young South American democracies during the period 1970-2007. The results, based on dynamic panel time-series analysis, robustly suggest that income growth has indeed played a progressive role in reducing inequality during the period. Moreover, the results suggest that this negative relationship is even stronger in the 1990s and early 2000s, a period in which the continent achieved macroeconomic stabilisation, political consolidation and much improved economic performance. On the contrary, during the 1980s (the so-called "lost decade"), the negative income growth experienced by the continent at the time has hit the poor the hardest, or alternatively speaking, it has played a regressive role on inequality. All in all, we suggest that consistent growth, and all that it encompasses, is an important equaliser which should not be discarded as a serious option by policy makers interested in a more equal income distribution.
\end{abstract}

Keywords: Growth, inequality, South America.

JEL Classification: E20, O11, O15, O54. 


\section{Introduction and Motivation}

South America has always presented interesting characteristics in terms of long-run development, and particularly in the last forty years or so the region has seen dramatic economic and political events taking place. To mention a few: erratic, negative and sometimes only modest economic growth rates (with a slightly positive trend over the period though), relatively high (but not immutable) income inequality, political regime changes towards more democratic institutions, high rates of inflation (and even hyperinflationary episodes in some instances), and finally macroeconomic stabilisation (in the spirit of Alesina and Drazen (1991)) and political consolidation (in the vein of Przeworski and Limongi (1997)).

However, in the last twenty years or so the region has seen a period of unprecedented economic and political stabilisation, with economic growth displaying a less erratic trend since the 1990s, a much improved macroeconomic performance (at least in terms of inflation rates), slightly lower inequality and, as we speak, not a single reversal to less democratic regimes.

Therefore, taking the above eventful economic and political background into account, and the always enriching debate about the role of economic growth in reducing, or increasing, income inequality, we investigate whether income growth has played any role on inequality in the young democracies of South America during 1970-2007. More specifically, some would argue that economic growth has the ability of raising all boats - particularly the boats of the poor - and consequently of reducing inequality. Essentially, in this case the poor would benefit as well as the rich from economic growth and all that it encompasses. On the other hand, others would argue that, particularly in developing countries, growth can leave the poorest poorer because of, for instance, trade liberalisation and technological changes, features which would leave those at the bottom of the distribution (who also happen to be unskilled) behind.

Moreover, in young and rather unequal democracies, with the extension of the political franchise, the poor are able to demand for particular redistributive policies based on transfers 
which might have an effect on inequality. On the other hand, the established elites, in principle, have their influence diluted by the democratic process, and consequently are not able to influence policy as during the political dictatorship periods, a factor which can also influence inequality. All the same, both effects might play a role on how inequality behaves in such an environment and the South American context offers us a rich ground for better understanding those possible relationships.

The sample we use for the analysis covers the period 1970-2007 and all nine South American young democracies (most of these countries transitioned from military dictatorships to more democratic regimes in the 1980s), and the empirical strategy, since the time-series variation is longer than the cross-sectional one $(T>N)$, is based on dynamic panel timeseries methods. The main results reported robustly suggest that income growth has played a small, but statistically significant, role in reducing inequality in the continent over the whole period.

In addition, we are also able to report that during the so-called "lost decade" of the 1980s, in which income was stagnant and growth displayed even negative rates at times, inequality increased. On the other hand, during 1990-2007, a period in which the continent achieved macroeconomic stabilisation and rather decent income growth rates, the Gini coefficient has, in fact, decreased. Therefore, we suggest that growth, and all the environment and institutional framework that it encompasses, is a serious potential equaliser that policy makers and other stakeholders interested in a more equal income distribution should not ignore. Moreover, the 1980s long recession hit the poor the hardest, which suggests that, for the sake of equality, recessions (and the bad policies that tend to cause them) should be avoided as well.

The literature has provided us with interesting, and sometimes even conflicting, results regarding the role of income growth on inequality. Initially, Li, Squire and Zou (1998), using a sample of 49 countries (the then newly released Deininger and Squire (1996) data set) and panel data methods, report that initial income reduces inequality. However, Easterly (1999), 
who also uses a panel of countries, reports that growth plays no role on inequality (his growth fixed effects estimates are not statistically significant). In addition, de Janvry and Sadoulet (2000) investigate twelve Latin American countries during the 1970-1994 period, to report that growth, as Easterly had done before, presents negative estimates, but not statistically significant, against inequality.

In what is probably the most cited study on the subject, Dollar and Kraay (2002), make use of a sample of 92 developing and developed countries over four decades, and the GMM estimator to report that "growth is good for the poor". Essentially, they suggest that the shares of the poorest quintile grow equiproportionately to average income. On the contrary, Lundberg and Squire (2003), make use of a larger sample than Dollar and Kraay (with 125 countries), to report that economic growth, in fact, increases the Gini coefficient in their broader sample.

Moreover, Lopez (2006) makes use of decadal dummies to better pinpoint the effect of growth on inequality during different periods of time in his panel of countries (he uses the Dollar and Kraay sample). Essentially, he reports that in the 1990s income growth is associated with higher inequality, and he suggests that the trade liberalisation and particular technological changes taking place in the 1990s are behind his results. Furthermore, Foster and Székely (2008) use data from 34 countries during 1976-2000 (their sample is composed mostly of Latin American countries), to report that the incomes of the poor do not increase equiproportionately with average incomes.

On a slightly different strand of the literature, Kuznets (1955) suggests that during the processes of long-run economic development that particular societies go through over time, income inequality increases in the short run, just to decrease in the long run. This prediction has prompted researchers to test for a non-linear relationship between income growth and inequality. On one hand, Spilimbergo, Londoño and Székely (1999) make use of a panel of 108 countries during 1947-1994 to report the absence of a Kuznets effect. On the other hand, Barro (2000) tests for the same Kuznets hypothesis and he is able to report some evidence 
in favour of it in his sample.

All in all, this brief, and non-exhaustive, literature review, and given the importance of the subject, suggests firstly that there is no clear verdict about the role of income growth on inequality, and secondly that a better understanding of this relationship is important for policy purposes and therefore welfare (particularly in developing countries). The former and the latter provide us with enough motivation for a better understanding of the South American context, a continent with its own idiosyncrasies and which, given its historical and present characteristics, provides us with a rich ground for a better understanding of this relationship.

Apart from the regional disaggregation we implement, which allow us to better understand the continent, and also to minimise generalisations which are not always warranted, we take advantage of dynamic panel time-series analysis which allows us to deal with interesting empirical issues - like heterogeneity, and statistical and economic endogeneity biases in dynamic panels - which have the potential to improve on previous estimates. The remainder of the paper is as follows: in the next Section we explain the data, the methodology used, and then we report and discuss the results obtained. In Section three we provide some final observations.

\section{Empirical Analysis}

\section{A. A Look at the Data}

The data set we use covers the period 1970-2007 and all nine South American young democracies, namely: Argentina, Bolivia, Brazil, Chile, Ecuador, Guyana, Paraguay, Peru and Uruguay ( $T=38$ and $N=9$ ). The Gini coefficients ( GINI) of income inequality come from the UNU-WIDER files. Income per capita $(G D P)$ and the economic growth rates $(G R O W)$ come from the Penn World Table (PWT) 6.3 files.

The control variables used are standard in the literature and they are as follows: the ratio of exports and imports to real GDP $(O P E N)$, which is a proxy for economic openness; 
and the government share to GDP $(G O V)$, a proxy for government size. Both variables come from the PWT files as well. The proxy for democracy is the rather popular, and normalised (ranging from zero to one), POLITY, which comes from the Polity IV files. The ratio of the liquid liabilities to GDP (M2), a measure of financial development, inflation (INFLAT), which is given by the usual transformation $\log \left(1+\left(\frac{I N F L A T}{100}\right)\right)$, is our proxy for macroeconomic performance, as well as urbanisation ( $U R B A N)$, a proxy for long-run development, come from the World Bank Development Indicators. Information on secondary education $(E D U C)$ is provided by the Barro and Lee (2010) files.

As an initial look at the data, in Figure One we plot the simple-averaged country time series over the period. In the first panel we plot the growth rates, and we can see not only the "lost decade" in the 1980s, with its negative growth rates, but also the positive growth rates taking place after the structural reforms of the 1990s. All in all, growth in the region has been far from consistent, nevertheless it seems that apart from the negative effect of an external shock (the Asian crisis) towards the end of the 1990s, the region has experienced better macroeconomic performance from the 1990s onwards than in the 1980s.

In the second panel we plot the averaged income per capita in logs over the period. Again, it is not difficult to visualise the "lost decade" and the economic stagnation associated with it, and also the recovery after the 1990s. Overall, income per capita presents a positive long-run trend in the region, even when taking into account the stagnant 1980s. Finally, in the bottom panel we plot inequality. Over time, the trend in inequality in the region seems to be positive, with a notable fall starting from the mid 1990s onwards, which coincides with the stabilisation and better economic performance period. 

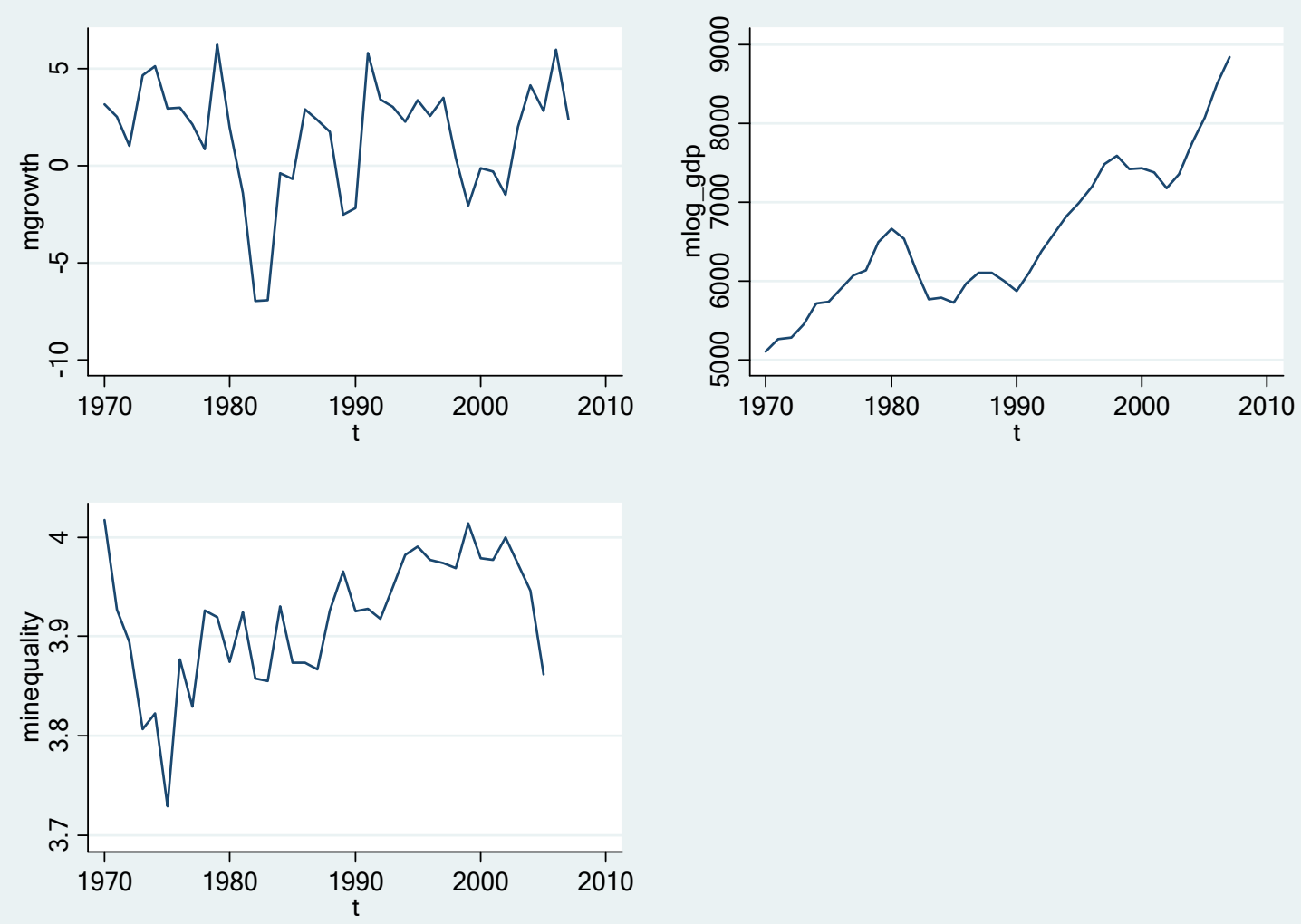

Figure 1: Economic growth $(G R O W)$, GDP per capita $(G D P)$, and Inequality $(G I N I)$, South America, 1970-2007. Source: PWT and UNU-WIDER files.

Moreover, in Table One we provide the correlation matrix amongst all variables used in the analysis. The statistical correlation that interests us mostly here is the one between the Gini coefficient of income inequality $(G I N I)$ and income per capita in logs $(G D P)$. This particular correlation is negative and statistically significant at the $5 \%$ level, and it indicates (without implying any causation at this early stage) that income growth is associated with lower inequality in this sample.

Another notable correlation is the one between inequality and $G O V$, the proxy for government size, which is negative and significant. This correlation is perhaps indicating that governments have the potential (via investment in social infrastructure) of reducing inequality. Moreover, $M 2$, our proxy for financial development, which is positive and significant, 
indicates that finance is not benefiting the bottom of the income distribution in a progressive manner (perhaps because of informational asymmetries in terms of accessing formal financial markets). In addition, the correlation between $U R B A N$ and inequality is negative and significant as well, which suggests that the urban sector of those economies tends to be less unequal than their rural counterparts (probably because the cities offer more dynamic job markets and employment opportunities).

Table One: The Correlation Matrix: South America, 1970-2007.

\begin{tabular}{|c|c|c|c|c|c|c|c|c|c|}
\hline & GDP & GINI & OPEN & GOV & POLITY & M2 & INFLAT & URBAN & EDUC \\
\hline GDP & 1 & & & & & & & & \\
\hline GINI & $-.377^{*}$ & 1 & & & & & & & \\
\hline OPEN & $-.554^{*}$ & .069 & 1 & & & & & & \\
\hline GOV & .019 & $-.196^{*}$ & $-.183^{*}$ & 1 & & & & & \\
\hline POLITY & $.151^{*}$ & $.210^{*}$ & $.175^{*}$ & $-.159^{*}$ & 1 & & & & \\
\hline M2 & $-.192^{*}$ & $.247^{*}$ & $.555^{*}$ & $-.108^{*}$ & $.222^{*}$ & 1 & & & \\
\hline INFLAT & $.122^{*}$ & -.123 & $-.431^{*}$ & $.191^{*}$ & .041 & $-.415^{*}$ & 1 & & \\
\hline URBAN & $.886^{*}$ & $-.340^{*}$ & $-.627^{*}$ & -.070 & $.216^{*}$ & $-.236^{*}$ & $.207^{*}$ & 1 & \\
\hline EDUC & $.172^{*}$ & $.225^{*}$ & $.349^{*}$ & $-.171^{*}$ & $.681^{*}$ & $.459^{*}$ & $-.137^{*}$ & $.235^{*}$ & 1 \\
\hline
\end{tabular}

Sources: PWT, UNU-WIDER, Polity IV, World Bank and Barro-Lee files. ${ }^{*}$ represents significance at the $5 \%$ level.

Furthermore, in Figure Two we plot the OLS regression lines between income growth and inequality in the continent. In the first panel we make use of the whole sample (1970-2007) and the regression line is slightly negative, which weakly confirms the negative correlation reported above and the prospective progressive role of income growth on inequality. In the second panel we plot only the 1980s data, and the line now is positive, which indicates that during the "lost decade" when income was stagnant and growth erratic-growth even presented negative rates at the time - the Gini coefficient increased. In the bottom panel we make use of data covering only the 1990s, and what we observe now is that the regression 
line becomes negative again, which indicates that during the recovery of the 1990s income growth played a progressive role on inequality in the region.
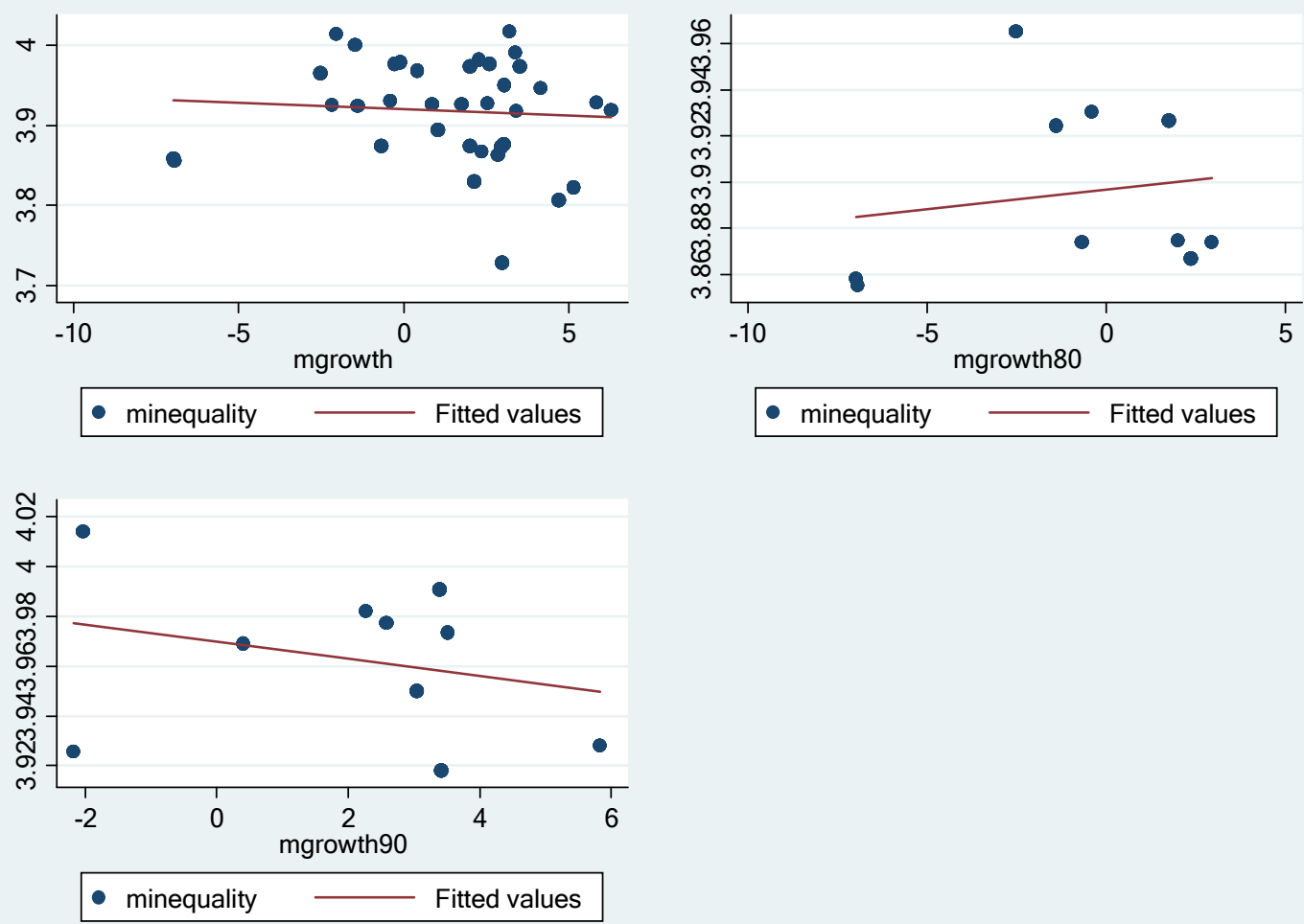

Figure 2: OLS regression lines. Economic growth $(G R O W)$ and Inequality $(G I N I)$, South America, 1970-2007. Source: PWT and UNU-WIDER files.

In essence, the above descriptive exercise (with all its caveats), and particularly the regression lines, suggest that there is an overall (negative) economic relationship between income growth and inequality in the continent, which coincidentally enough is stronger in the 1990s, the decade that the continent saw a number of structural reforms taking place (e.g., the import substitution model, and all that it encompasses, came to an end in most countries and particular economic policies that lead to macroeconomic stability were implemented), which in turn might have played a role on income growth and consequently on inequality. On the contrary, during the 1980s, or the "lost decade", income growth did not play the same sort of progressive role on inequality, perhaps because of the stagnant income and negative 
growth rates that took place at the time, which tends to hurt mostly the poor.

\section{B. Empirical Strategy}

In terms of empirical strategy, since we have a $T>N$ data set and also assuming that inequality is a persistent variable, the strategy followed is based on dynamic panel time-series analysis. This is interesting in itself because, apart from dealing with relevant empirical issues in relatively thin panels - heterogeneity and endogeneity biases - the panel time-series analysis allows us to conduct a more disaggregated study of South America, which furthers our knowledge of the region. Basically, we are able to specifically study the South American experience, avoiding particular generalisations and without treating the region either as a dummy or as an outlier to be discarded from the sample ${ }^{1}$.

Firstly, the issue of the Nickell bias in dynamic $T>N$ panels, which is of order $\bigcirc(1 / T)$, and is caused because the Fixed Effects (FE) transformed error term tends to be correlated with the lagged dependent variable, is less of a problem when $T$ is increasing in size. Therefore, we use the Fixed Effects estimator (with robust standard errors) which provides consistent estimates in dynamic models when $T \rightarrow \infty$ (Smith and Fuertes (2010)), and as $T \rightarrow \infty$ we are able to minimise the Nickell bias and also statistical endogeneity (Judson and Owen (1999)). The estimated dynamic equation is as follows:

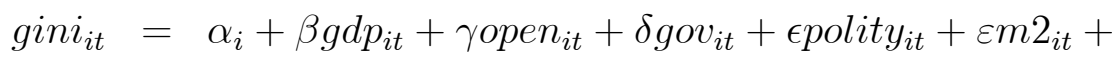

$$
\begin{aligned}
& +\zeta \inf l_{a t}+\operatorname{\eta urban}_{i t}+\theta e d u c_{i t}+\vartheta \operatorname{gini}_{i t-1}+v_{i t},
\end{aligned}
$$

where GINI is our measure of inequality in logs, GDP is income per capita in logs, $O P E N$ is our proxy for trade openness, GOV is our proxy for government size, POLITY is our proxy for democracy, $M 2$ is a measure of financial development, INFLAT is inflation and it proxies for macroeconomic stability, $U R B A N$ is the share of the population living in urban areas and a proxy for long-run development, and $E D U C$ is a proxy for education. 
Secondly, we follow Lopez (2006) and introduce in our FE regressions interaction terms between income growth and dummies covering the 1980s and 1990-2007 respectively, with zeros elsewhere. With those interaction terms we can better understand the role of the "lost decade" on inequality, and then the behaviour of inequality during the period in which the continent saw structural changes with the implementation of particular economic policies and institutions, like trade liberalisation and central bank independence. The estimated equation is as follows:

$$
\begin{aligned}
& \text { gini }_{i t}=\alpha_{i}+E I T H E R \beta_{1} g d p 80_{i t} O R \beta_{2} g d p 90-07_{i t}+\gamma o p e n_{i t}+\delta g o v_{i t}+ \\
& + \text { ppolity }_{i t}+\varepsilon m 2_{i t}+\zeta \inf l_{a t}+\text { qurban }_{i t}+\theta e d u c_{i t}+\vartheta g i n i_{i t-1}+v_{i t},
\end{aligned}
$$

where GDP80 and GDP90 - 07 are our interaction terms between income growth and the respective decade (1980s) or time period (1990-2007) being studied, with zeros elsewhere.

Thirdly, although we use the variables and controls suggested by the previous literature, it can be argued that there are some omitted variables or measurement error present. In addition, some would argue that there is reverse causality present as well (e.g., Persson and Tabellini (1994), Clarke (1995), Forbes (2000) and Panizza (2002) all suggest that inequality, in one way or another, determines income growth). We therefore use the Fixed Effects with Instrumental Variables (FE-IV) two-stage Least Squares estimator, and with the Solovian assumption in mind $(\dot{k}=s y)$ - (Solow $(1956)$ - we make use of investment share to GDP $(I N V)$ from PWT 6.3 as our external identifying instrument for contemporaneous income growth. The estimates provided by the FE-IV estimator are asymptotically consistent and efficient as $T \rightarrow \infty$, and it retains the time series consistency even if the instrument set is only predetermined (Arellano $(2003))^{2}$. 
The estimated second-stage dynamic equation is as follows:

$$
\begin{aligned}
& \text { gini }_{i t}=\alpha_{i}+\beta g d p_{i t}+\text { ropen }_{i t}+\text { ggov }_{i t}+\text { epolity }_{i t}+\varepsilon m 2_{i t}+ \\
& +\zeta \inf l a t_{i t}+\operatorname{\eta urban}_{i t}+\theta e d u c_{i t}+\vartheta g_{i n i} i_{i t-1}+v_{i t},
\end{aligned}
$$

with investment in the first-stage regression serving as the identifying instrument for income growth.

Essentially, although these countries experienced political transitions and shared similar poor macroeconomic characteristics in the 1980s and early 1990s, these Fixed Effects estimators account not only for important econometric issues - heterogeneity bias and endogeneity but also for the fact that some of these countries do indeed present their own idiosyncrasies, such as different levels of economic development (e.g., Argentina and Brazil are known to be relatively more developed than Bolivia and Peru).

\section{Results and Discussion}

In what follows we estimate baseline regressions of income growth against inequality with the most popular control variables previously used by the literature and then we insert other controls also used before in a stepwise fashion for robustness sake.

In Table Two we report the FE dynamic estimates of income growth $(G D P)$ on inequality $(G I N I)$ using the variation during the whole period. Essentially, the GDP estimates are all negative and statistically significant against inequality during the period (and they are similar, at least in terms of size, to the ones reported by Lopez (2006)). For instance, the $G D P$ estimate in regression five indicates that a point increase in income has the ability of reducing inequality in .09 points. All the same, these estimates suggest that income growth has affected the bottom of the income distribution in a fashion that has reduced overall inequality (e.g., Li, Squire and Zou (1998) and Dollar and Kraay (2002)).

To put it another way, perhaps income growth in South America has relied on the 
services sector (which also includes the rather large informal sector seen in the continent) and these sectors make use mostly of people with some technical skills (e.g. sales, computing, office work, etc.) who happen to be at the lower tail of the distribution, and not so much on highly skilled people with tertiary education (e.g., de Janvry and Sadoulet (2000)).

About the controls, trade openness $(O P E N)$ is not entirely significant across the different regressions, however regressions four and five indicate that openness plays a regressive role on inequality. This regressive effect of openness on the Gini coefficient is perhaps illustrating the role of skills (or factor endowments) when processes of trade liberalisation take place, or that those benefiting most from openness are those with tertiary education (e.g., Spilimbergo, Londoño and Székely (1999) and Barro (2000)).

The control for macroeconomic performance, inflation (INFLAT), as one would expect in South America, has had the effect of increasing inequality in the continent. This inflation effect is because South America experienced episodes of high inflation, and even some bursts of hyperinflation, in countries like Argentina, Bolivia, Brazil and Peru, and the poor, for not having access to indexed financial assets and for carrying more cash than the better off end up paying the regressive inflation tax (e.g., de Janvry and Sadoulet (2000) and Foster and Székely $(2008))^{3}$.

Moreover, our proxy for financial development, (M2), presents positive and significant estimates against inequality, however one would expect negative ones (e.g., Li, Squire and Zou (1998)). These negative estimates are perhaps illustrating the fact that the poorest have less experience, and even lack information, on how to make formal financial markets work in their favour in terms of investment opportunities (Foster and Székely (2008)) ${ }^{4}$.

Another interesting result is the one associated with urbanisation, (URBAN), which indicates that the long-run process of migration to the cities that has taken place in South America has helped to reduce the Gini coefficient (de Janvry and Sadoulet (2000) report similar estimates, however their static random effects estimates are not entirely statistically significant). In other words, it is perhaps easier to find employment (including jobs in the 
informal sector) and also to acquire education in cities than in rural areas (Kuznets (1955)). Finally, the first lag of inequality $\left(G I N I_{1}\right)$ is positive and statistically significant, which confirms the fact that inequality is a slow-moving variable.

Table Two: Dynamic FE Estimates, South America, 1970-2007.

\begin{tabular}{|c|c|c|c|c|c|}
\hline GINI & 1 & 2 & 3 & 4 & 5 \\
\hline GDP & $-.055(-2.42)$ & $-.063(-2.42)$ & $-.060(-1.99)$ & $-.081(-2.93)$ & $-.093(-3.28)$ \\
\hline OPEN & $.086(1.59)$ & $.072(1.22)$ & $.090(1.70)$ & $.131(2.96)$ & $.114(2.73)$ \\
\hline GOV & $-.073(-0.92)$ & $-.078(-1.09)$ & $-.093(-1.38)$ & $-.078(-1.35)$ & $-.052(-0.97)$ \\
\hline POLITY & $-.008(-0.75)$ & $-.007(-0.66)$ & $-.011(-0.93)$ & $-.005(-0.39)$ & $-.011(-0.94)$ \\
\hline M2 & & $.019(2.39)$ & $.024(1.99)$ & $.034(3.05)$ & $.032(3.07)$ \\
\hline INFLAT & & & $.017(3.76)$ & $.019(4.26)$ & $.017(3.43)$ \\
\hline URBAN & & & & $-.369(-1.95)$ & $-.737(-1.99)$ \\
\hline EDUC & & & & & $.097(1.37)$ \\
\hline $\mathrm{GINI}_{1}$ & $.498(6.08)$ & $.485(5.74)$ & $.468(6.79)$ & $.476(7.70)$ & $.461(6.30)$ \\
\hline F test & 41.68 & 35.16 & 31.97 & 29.99 & 27.65 \\
\hline $\mathrm{F}^{*}$ test & 6.23 & 6.42 & 7.08 & 7.46 & 8.05 \\
\hline $\mathrm{R}^{2}$ & 0.59 & 0.61 & 0.58 & 0.51 & 0.49 \\
\hline
\end{tabular}

T-ratios in parentheses. Number of observations: $N T=342$. GINI are the Gini coefficients, $G D P$ is the GDP per capita in logs, $O P E N$ is a measure for trade openness, GOV the government share to GDP, POLITY is a proxy for democracy, M2 are the liquid liabilities to GDP, INFLAT are the inflation rates, $U R B A N$ is the share of urban population and $E D U C$ is secondary education. FE is the Fixed Effects estimator.

In Table Three we report the dynamic FE estimates, but now we use our interaction term between income growth and the decadal dummy for the 1980s (GDP80), with zeros elsewhere. All GDP80 estimates are positive and statistically significant, which indicates that the "lost decade", or the stagnation of the 1980s, played a regressive role on inequality. All the same, these estimates are somehow expected, in times of macroeconomic instability 
and lack of income growth, those being affected mostly by recessions and rising unemployment are the poor and unskilled (e.g., de Janvry and Sadoulet (2000)). For instance, a point reduction in income increases inequality in .002 points.

Furthermore, the estimates of trade openness are all positive and mostly significant this time, forcibly suggesting that trade openness in South America benefits mostly those who are highly skilled in the distribution. Inflation, given its nature in the continent in the 1980s and early 1990s, keeps its regressive and significant effect on inequality, and the lagged-dependent variable maintains its significant persistence over time.

Table Three: Dynamic FE Estimates, South America, 1970-2007.

\begin{tabular}{lccccc}
\hline \hline GINI & 1 & 2 & 3 & 4 & \multicolumn{1}{c}{5} \\
\hline GDP80 & $.002(3.18)$ & $.002(2.57)$ & $.003(2.92)$ & $.002(2.52)$ & $.002(2.79)$ \\
OPEN & $.098(2.11)$ & $.094(1.62)$ & $.116(2.45)$ & $.144(3.22)$ & $.130(3.01)$ \\
GOV & $-.056(-1.23)$ & $-.056(-1.23)$ & $-.074(-1.56)$ & $-.055(-1.67)$ & $-.038(-0.99)$ \\
POLITY & $-.007(-0.84)$ & $-.007(-0.78)$ & $-.011(-1.15)$ & $-.006(-0.57)$ & $-.009(-0.90)$ \\
\hline M2 & & $.004(0.35)$ & $.009(0.88)$ & $.017(1.52)$ & $.017(1.46)$ \\
INFLAT & & & $.018(3.75)$ & $.020(4.62)$ & $.019(3.84)$ \\
URBAN & & & & $-.286(-1.48)$ & $-.469(-1.41)$ \\
EDUC & & & & & $.048(0.88)$ \\
GINI 1 & $.487(6.02)$ & $.487(6.03)$ & $.466(6.96)$ & $.481(8.23)$ & $.481(7.81)$ \\
F test & 44.01 & 36.34 & 33.45 & 30.47 & 27.09 \\
F* test & 7.38 & 7.28 & 8.13 & 7.81 & 7.82 \\
R $^{2}$ & 0.56 & 0.58 & 0.52 & 0.52 & 0.54 \\
\hline \hline
\end{tabular}

T-ratios in parentheses. Number of observations: $N T=342 . G I N I$ are the Gini coefficients, $G D P 80$ is the GDP per capita in logs in the 1980s with zeros elsewhere, $O P E N$ is a measure for trade openness, GOV the government share to GDP, POLITY is a proxy for democracy, M2 are the liquid liabilities to GDP, INFLAT are the inflation rates, $U R B A N$ is the share of urban population and $E D U C$ is secondary education. FE is the Fixed Effects estimator. 
In Table Four we regress our interaction term between income growth and the dummy for the period 1990-2007 (GDP90 - 07), with zeros elsewhere. This period is interesting because South America achieved macroeconomic stabilisation, with the implementation of particular economic policies and institutions (which includes trade liberalisation and fiscal responsibility laws), and it has also managed to consolidate its democratic institutions. These GDP90-07 estimates are all negative and significant, which indicate that during this period of economic recovery, not to mention the real income growth that has taken place since then, income has played a progressive role on inequality. For instance, a point increase in income reduces the Gini in .006 points.

Furthermore, trade openness keeps its positive and significant estimates, confirming that trade openness in South America tends to benefit those with higher education mostly, as well as inflation which keeps its regressive effect on inequality. An interesting surprise is that the proxy for government size, $(G O V)$, presents negative and significant estimates. This result is probably reflecting better governance and therefore better spending (e.g., in social infrastructure) of public money (Foster and Székely (2008)). It must be said though, that this variable is highly aggregated and therefore it becomes difficult to draw more solid conclusions about the role of government on inequality. No doubt this is an issue that deserves more attention, as long as more disaggregated data become available. The lagged dependent variable keeps its persistent role against itself. 
Table Four: Dynamic FE Estimates, South America, 1970-2007.

\begin{tabular}{lccccc}
\hline \hline GINI & 1 & 2 & 3 & 4 & \multicolumn{1}{c}{5} \\
\hline GDP90-07 & $-.006(-2.86)$ & $-.006(-2.54)$ & $-.007(-3.06)$ & $-.006(-2.97)$ & $-.006(-3.31)$ \\
OPEN & $.139(2.78)$ & $.136(2.28)$ & $.174(3.80)$ & $.177(3.94)$ & $.161(3.95)$ \\
GOV & $-.080(-2.28)$ & $-.079(-2.32)$ & $-.105(-3.20)$ & $-.094(-3.38)$ & $-.068(-2.31)$ \\
POLITY & $-.000(-0.08)$ & $-.000(-0.08)$ & $-.004(-0.45)$ & $-.002(-0.27)$ & $-.008(-0.83)$ \\
\hline M2 & & $.002(0.31)$ & $.007(0.83)$ & $.011(1.71)$ & $.009(1.15)$ \\
INFLAT & & & $.022(4.72)$ & $.022(4.94)$ & $.021(4.11)$ \\
URBAN & & & & $-.118(-0.57)$ & $-.406(-1.17)$ \\
EDUC & & & & & $.078(1.27)$ \\
GINI & $.487(5.82)$ & $.487(5.85)$ & $.458(6.39)$ & $.468(7.11)$ & $.461(6.07)$ \\
F test & 46.26 & 38.17 & 36.40 & 31.76 & 28.83 \\
F* test $^{*}$ & 8.14 & 8.02 & 9.50 & 8.44 & 8.81 \\
$\mathrm{R}^{2}$ & 0.44 & 0.45 & 0.36 & 0.40 & 0.47 \\
\hline \hline
\end{tabular}

T-ratios in parentheses. Number of observations: NT =342. GINI are the Gini coefficients, GDP90-

07 is the GDP per capita in logs in 1990-2007 with zeros elsewhere, OPEN is a measure for trade openness, GOV the government share to GDP, POLITY is a proxy for democracy, M2 are the liquid liabilities to GDP, INFLAT are the inflation rates, $U R B A N$ is the share of urban population and $E D U C$ is secondary education. FE is the Fixed Effects estimator.

Lastly, in Table Five we account for possible endogeneity and report the second-stage dynamic FE-IV estimates. All instrumented GDP estimates are negative and statistically significant against inequality. The estimates themselves are bigger in size than the ones reported before because of the external variation provided by our identifying instrument, investment (which is positive and significant in the first-stage regressions) ${ }^{5}$. Essentially, these negative income estimates are somehow confirming the progressive role of growth in reducing the Gini coefficient, or in positively affecting the lower tail of the income distribution in South America during the eventful period of 1970-2007. 
Furthermore, openness and inflation maintain their regressive roles on inequality, and GOV presents once again mostly significant negative estimates. Moreover, the positive and significant $M 2$ estimates indicate the existence of asymmetries in terms of access to formal financial markets, and the negative $U R B A N$ estimates suggest again that inequality tends to be lower in the cities. The lagged dependent variable keeps its persistent effect against itself.

Table Five: Dynamic FE-IV Estimates, South America, 1970-2007.

\begin{tabular}{lrrrrr}
\hline \hline GINI & 1 & 2 & 3 & 4 & 5 \\
\hline GDP & $-.143(-1.88)$ & $-.157(-2.01)$ & $-.137(-1.80)$ & $-.172(-2.19)$ & $-.172(-2.24)$ \\
OPEN & $.101(3.83)$ & $.084(2.99)$ & $.099(3.49)$ & $.149(4.28)$ & $.126(3.64)$ \\
GOV & $-.112(-2.14)$ & $-.120(-2.26)$ & $-.126(-2.43)$ & $-.114(-2.24)$ & $-.078(-1.55)$ \\
POLITY & $-.008(-1.25)$ & $-.008(-1.15)$ & $-.011(-1.61)$ & $-.004(-0.61)$ & $-.012(-1.50)$ \\
\hline M2 & & $.024(1.48)$ & $.028(1.78)$ & $.041(2.46)$ & $.037(2.30)$ \\
INFLAT & & & $.017(2.11)$ & $.019(2.43)$ & $.017(2.12)$ \\
URBAN & & & & $-.434(-2.61)$ & $-.852(-3.09)$ \\
EDUC & & & & & $.113(2.01)$ \\
GINI 1 & $.455(5.21)$ & $.437(4.91)$ & $.429(4.94)$ & $.433(5.06)$ & $.422(4.97)$ \\
F test & 40.40 & 33.92 & 31.16 & 28.84 & 26.74 \\
F* test & 6.26 & 6.43 & 7.07 & 7.19 & 7.65 \\
R $^{2}$ & 0.49 & 0.50 & 0.50 & 0.43 & 0.44 \\
\hline \hline
\end{tabular}

T-ratios in parentheses. Number of observations: $N T=342$. GINI are the Gini coefficients, $G D P$ is the GDP per capita in logs, $O P E N$ is a measure for trade openness, GOV the government share to GDP, POLITY is a proxy for democracy, M2 are the liquid liabilities to GDP, INFLAT are the inflation rates, $U R B A N$ is the share of urban population and $E D U C$ is secondary education. FE-IV is the Fixed Effects with Instrumental Variables estimator and investment $(I N V)$ is the identifying instrument for $G D P$.

It is worth mentioning at this stage that in all tables above the $\mathrm{F}^{*}$ tests suggest that we can reject the null of homogeneous intercepts, which validates the use of the Fixed Effects 
estimator. Secondly, given that all these countries are young democracies and relatively unequal, we would expect the variable POLITY, our proxy for democratisation, to play a progressive role on inequality. Essentially, without the constraints imposed by those military juntas, demand for redistribution would be higher in those young democracies, and perhaps inequality lower. On the other hand, in dictatorships the rich would be able to lobby for particular economic policies that would benefit themselves (Barro (2000)). Overall, given the nature of the estimates reported, and also that democratisation took place in different countries at different points in time (but mostly in the 1980s), it is plausible that both effects are cancelling each other out in South America.

Also important to mention, the income growth estimates reported above are in line with some of the previous studies, e.g. Li, Squire and Zou (1998) and Dollar and Kraay (2002), at least in terms of income growth and reduced inequality, or higher incomes of the poor. On the other hand, our estimates contrast with the ones provided by de Janvry and Sadoulet (2000) and also Lopez (2006). This is perhaps because we have more data (which includes the economic recovery of the 1990s and 2000s) and take advantage of better estimation techniques, that deal with heterogeneity and endogeneity in dynamic panels, than de Janvry and Sadoulet (2000). In the case of Lopez (2006), we find that, at least in South America, the period 1990-2007 has seen a decrease in inequality instead. The latter highlights the importance of regional disaggregations that can have the effect of reducing unwarranted generalisations about the role of income growth on inequality. All in all, the role of the various changes taking place in different regions of the world in the 1990s is an interesting issue that deserves more attention.

In a nutshell, by accounting for heterogeneity bias and endogeneity concerns in dynamic panel time-series, we find that income growth plays a robust progressive role on inequality in South America ${ }^{6}$. In addition, the long economic and political instability of the 1980s, illustrated by a long and protracted recession, had the effect of increasing the Gini coefficient in the continent, which confirms the long-held view that recessions hurt the poor the hardest. 
Furthermore, coincidentally enough, after the reforms, stabilisation and consolidation of the early 1990s, economic activity resumed and income growth has played the expected role in reducing inequality, which highlights once again the importance of consistent economic activity (and all that it encompasses) in reducing inequality.

\section{Final Observations}

We have investigated whether income growth increased, or reduced, income inequality in the young democracies of South America in 1970-2007. The results, based on dynamic panel time-series analysis, suggest that income growth has had the effect of reducing inequality in the continent. Moreover, the protracted recession and poor macroeconomic performance seen in the 1980s has hurt the poor the hardest, with inequality increasing at the time. Furthermore, after the stabilisation, and structural reforms taking place in the 1990s, income growth has played a progressive role on inequality.

In addition, the results suggest that poor macroeconomic performance, in terms of high inflation, tends to be regressive on inequality, therefore the importance of institutions (e.g., central bank independence) and policies (e.g., fiscal rules) which are conducive to macroeconomic stability and therefore growth, and that were implemented in South America only in the 1990s. Moreover, although education per se is not entirely meaningful in the above analysis, our proxies for openness and financial development indicate that education plays an indirect role on inequality as well, in the sense that human capital is an important safety net in open and technologically driven societies, and also because it allows people to make good use of finance. Finally, the long-run process of urbanisation taking place in the continent, seems to offer better prospects in terms of lower inequality than life in rural areas.

Future work can be extended to other regions, e.g., it would be interesting to see whether the recent income growth seen in sub-Saharan Africa has played any role on poverty, since poverty is a more pressing issue in the region. In this particular case, given the number of countries, the methodology would be based on panel data $(N \geq T)$. All the same, such 
disaggregations can shed some light on how income, inequality and other welfare variables behave in different regions and continents. Furthermore, with historical data on income and inequality we could test for the Kuznets hypothesis in the South American continent, which would certainly enrich our knowledge of the region.

To conclude, we suggest that growth (and all the institutional framework and environment that it encompasses) is a prospective - and perhaps non-intrusive equaliser which should not be overlooked by policy makers and other stakeholders interested in a more equal income distribution, particularly in developing countries. Ultimately, it is also always worth mentioning that without economic activity, or growth, it becomes difficult to fund particular, and alternative, redistributive policies like public transfers which specifically target the poor. Ultimately, growth matters and it can be good for all, including the poor.

\section{REFERENCES}

Alesina, Alberto, and Allan Drazen. 1991. Why are stabilizations delayed? American Economic Review 81 (5).

Arellano, M. "Panel data econometrics." Oxford University Press: Advanced texts in Econometrics, 2003.

Barro, Robert J. 2000. Inequality and Growth in a Panel of Countries. Journal of Economic Growth 5:5-32.

Barro, Robert, and Jong-Wha Lee. 2010. A new data set of educational attainment in the world, 1950-2010. In NBER Working Paper no. 15902.

Beck, T., A. Demirgüç-Kunt, and R. Levine. 2007. Finance, inequality, and the poor. Journal of Economic Growth 12 (1).

Bittencourt, Manoel. 2010. Financial development and inequality: Brazil 1985-1994. Economic Change and Restructuring 43 (2). 
Bittencourt, Manoel. 2009. Macroeconomic Performance and Inequality: Brazil, 1983-94. The Developing Economies 47 (1):30-52.

Bond, Stephen R. 2002. Dynamic Panel Data Models: A Guide to Micro Data Methods and Practice. Portuguese Economic Journal 1 (2):141-62.

Clarke, George R.G. 1995. More evidence on income distribution and growth. Journal of Development Economics 47:403-427.

Deininger, K and Squire, L. 1996. Measuring income inequality: a new data base. The World Bank Economic Review 10:565-591.

Dollar, David. 2002. Growth is Good for the Poor. Journal of Economic Growth 7:195-225.

Easterly, William. 1999. Life During Growth. Journal of Economic Growth 4 (3):239-275.

Easterly, William, and Stanley Fischer. 2001. Inflation and the Poor. Journal of Money, Credit and Banking 33 (2):160-178.

Forbes, Kristin J. 2000. A Reassessment of the Relationship between Inequality and Growth. The American Economic Review 90 (4):869-887.

Foster, James E., and Miguel Székely. 2008. Is economic growth good for the poor? Tracking low incomes using general means. International Economic Review 49 (4):1143-1172.

Heston, Alan, Robert Summers, and Bettina Aten. Penn World Table version 6.3 Center for International Comparisons of Production, Income and Prices at the University of Pennsylvania, 2009 [cited.

Janvry, Alain de, and Elisabeth Sadoulet. 2000. Growth, poverty, and inequality in Latin America: A causal analysis, 1970-94. Review of Income and Wealth 46 (3):267-287.

Judson, Ruth A., and Ann L. Owen (1999). "Estimating Dynamic Panel Data Models: A Guide for Macroeconomists," Economics Letters, vol. 65, no. 1, pp. 9-15. 
Kuznets, Simon. 1955. Economic growth and income inequality. American Economic Review $45(1)$.

Li, Hongyi, Lyn Squire, and Heng-fu Zou. 1998. Explaining international and intertemporal variations in income inequality. The Economic Journal 108:26-43.

Lopez, Humberto. 2006. Growth and inequality: Are the 1990s different? Economic Letters 93:18-25.

Lundberg, Mattias, and Lyn Squire. 2003. The Simultaneous Evolution of Growth and Inequality. The Economic Journal 113 (487):326-344.

Marshall, Monty, and Keith Jaggers. Polity IV project: political regime characteristics and transitions, 1800-2010 Center for Systemic Peace, 2010 [cited.

Panizza, Ugo. 2002. Income Inequality and Economic Growth: Evidence from American Data. Journal of Economic Growth 7:25-41.

Persson, Torsten, and Guido Tabellini. 1994. Is Inequality Harmful for Growth? The American Economic Review 84 (3):600-621.

Przeworski, Adam and Fernando Limongi. 1997. Modernization: theories and facts. World Politics 49 (2):155-183.

Smith, Ron, and Ana-Maria Fuertes. 2010. Panel Time-Series. In London: Centre for Microdata Methods and Practice. Institute for Fiscal Studies.

Solow, Robert. 1956. A Contribution to the Theory of Economic Growth. Quarterly Journal of Economics 70:65-94.

Spilimbergo, Antonio, Juan Luis Londoño, and Miguel Székely. 1999. Income distribution, factor endowments, and trade openness. Journal of Development Economics 59:77-101. 
Swamy, P.A.V.B. 1970. Efficient Inference in a Random Coefficient Regression Model. Econometrica 38 (2):311-323. 


\section{Notes}

*Department of Economics, University of Pretoria, Lynnwood Road, Pretoria 0002, RSA, e-mail: manoel.bittencourt@up.ac.za. I thank seminar participants at Pretoria for comments.

${ }^{1}$ For instance, Barro (2000) and Dollar and Kraay (2002) make use of dummies for Latin America.

${ }^{2}$ Perhaps it is worth mentioning that, for instance, Bond (2002) argues that GMM-type estimators are not an alternative under $T>N$ because of the overfitting problem.

${ }^{3}$ These results are in accordance with a parallel literature which deals explicitly with the role of inflation on inequality. For instance, Easterly and Fischer (2001) suggest that the poor from 38 countries consider inflation to be a more pressing problem than the rich, and Bittencourt (2009) reports that the high rates of inflation seen in Brazil in 1983-1994 contributed to increase earnings inequality.

${ }^{4} \mathrm{~A}$ parallel literature suggests that access to finance can reduce inequality, e.g., Beck, Demirgüç-Kunt and Levine (2007) and Bittencourt (2010).

${ }^{5}$ In the first-stage regressions, the identifying instrument is always statistically significant, and positive, against income growth. Moreover, the F tests are also statitically significant in all first-stage regressions. Available on request.

${ }^{6}$ We have also used the Random Coefficients estimator proposed by Swamy (1970), which allows for heterogeneity of intercepts and slopes. The estimates are in line with our FE estimates. Available on request. 